\title{
Dicer-2 promotes mRNA activation through cytoplasmic polyadenylation
}

\author{
OLGA COLL, ${ }^{1,2,4}$ TANIT GUITART, ${ }^{1,2,4}$ ANA VILLALBA, ${ }^{1,2,4}$ CATHERINE PAPIN, ${ }^{3}$ MARTINE SIMONELIG, ${ }^{3}$ \\ and FÁTIMA GEBAUER ${ }^{1,2}$ \\ ${ }^{1}$ Gene Regulation, Stem Cells and Cancer Programme, Centre for Genomic Regulation (CRG), The Barcelona Institute of Science and Technology, \\ 08003-Barcelona, Spain \\ ${ }^{2}$ Universitat Pompeu Fabra (UPF), 08003-Barcelona, Spain \\ ${ }^{3}$ Institute of Human Genetics, CNRS UMR9002-University of Montpellier, mRNA Regulation and Development, 34396-Montpellier, France
}

\begin{abstract}
Cytoplasmic polyadenylation is a widespread mechanism to regulate mRNA translation. In vertebrates, this process requires two sequence elements in target $3^{\prime}$ UTRs: the U-rich cytoplasmic polyadenylation element and the AAUAAA hexanucleotide. In Drosophila melanogaster, cytoplasmic polyadenylation of Toll mRNA occurs independently of these canonical elements and requires a machinery that remains to be characterized. Here we identify Dicer-2 as a component of this machinery. Dicer-2, a factor previously involved in RNA interference (RNAi), interacts with the cytoplasmic poly(A) polymerase Wispy. Depletion of Dicer-2 from polyadenylation-competent embryo extracts and analysis of wispy mutants indicate that both factors are necessary for polyadenylation and translation of Toll mRNA. We further identify r2d2 mRNA, encoding a Dicer-2 partner in RNAi, as a Dicer-2 polyadenylation target. Our results uncover a novel function of Dicer-2 in activation of mRNA translation through cytoplasmic polyadenylation.
\end{abstract}

Keywords: Dicer-2; Wispy; translation; cytoplasmic polyadenylation

\section{INTRODUCTION}

Dynamic regulation of the mRNA poly(A) tail length allows rapid and accurate control of gene expression in time and space. In oocytes and embryos, a long poly(A) tail promotes translation, while poly $(\mathrm{A})$ tail shortening beyond a certain threshold leads to mRNA decapping and degradation (Zhang et al. 2010; Eckmann et al. 2011; Subtelny et al. 2014). Cytoplasmic poly(A) tail elongation stimulates mRNA translation and stability in a wide variety of biological situations, including oocyte maturation, early embryonic development, neuronal plasticity, cell proliferation and senescence, cell identity, inflammation, metabolism, circadian gene expression and hibernation (Kojima et al. 2012; Weill et al. 2012; Ivshina et al. 2014; Elewa et al. 2015; Grabek et al. 2015).

The biochemistry of cytoplasmic polyadenylation has been deciphered in vertebrates, where two sequences in the $3^{\prime}$ UTR of substrate mRNAs are required: the U-rich cytoplasmic polyadenylation element $(\mathrm{CPE})$ and the $\mathrm{A}(\mathrm{A} / \mathrm{U}) \mathrm{UAAA}$ polyadenylation hexanucleotide (Hex). The CPE is recognized by the CPE-binding protein (CPEB, a family of four members)

\footnotetext{
${ }^{4}$ These authors contributed equally to this work.

Corresponding author: fatima.gebauer@crg.eu

Article is online at http://www.rnajournal.org/cgi/doi/10.1261/rna.065417.

117. Freely available online through the RNA Open Access option.
}

while the Hex is bound by the multisubunit cleavage and polyadenylation specificity factor (CPSF). Together with the scaffolding protein Symplekin, these factors recruit the cytoplasmic poly(A) polymerase GLD-2 to elongate the adenosine tail at the $3^{\prime}$ end of the mRNA (for review, see Villalba et al. 2011; Weill et al. 2012; Ivshina et al. 2014). The poly $(\mathrm{A})$ tail is then recognized by $\operatorname{poly}(\mathrm{A})$-binding protein (PABP), which contacts the cap-binding complex at the $5^{\prime}$ end of the mRNA to stimulate translation initiation.

The cytoplasmic polyadenylation machinery is conserved in Drosophila melanogaster. During late oogenesis in this organism, the CPEB1 homolog Orb and the Wispy poly(A) polymerase-which belongs to the GLD-2 family-function to promote the polyadenylation of several mRNAs (Chang et al. 1999; Benoit et al. 2008; Cui et al. 2008, 2013; Norvell et al. 2015). Wispy also polyadenylates a large number of maternal mRNAs during the first $2 \mathrm{~h}$ of embryogenesis, a time that concurs with little or no transcription (Benoit et al. 2008; Cui et al. 2008, 2013; Eichhorn et al. 2016; Lim et al. 2016). During these early stages of development, there is no expression of Orb, and a weak expression of the CPEB2-4 homolog Orb2 is detected, suggesting that CPEB-

(C) 2018 Coll et al. This article, published in RNA, is available under a Creative Commons License (Attribution 4.0 International), as described at http://creativecommons.org/licenses/by/4.0/. 
independent mechanisms of cytoplasmic polyadenylation might ensue (Vardy and Orr-Weaver 2007; Rangan et al. 2009; Hafer et al. 2011). Indeed, the polyadenylation of the transcript encoding the morphogen and innate immunity effector Toll occurs independently of the CPE and Hex (Coll et al. 2010). Importantly, titration experiments showed that polyadenylation of Toll is not competed by RNAs containing functional CPEs and Hex, indicating that an alternative, noncanonical machinery is responsible for polyadenylation of this transcript (Coll et al. 2010). A fragment of Toll $3^{\prime}$ UTR located after the stop codon (termed "polyadenylation region" or PR) retained polyadenylation capacity and was able to efficiently compete polyadenylation of Toll, suggesting that relevant factors bind to this region.

Here we identify Dicer-2 as a component of the noncanonical machinery that binds to PR. Initial experiments showed that Wispy, but not Orb2 or Symplekin, binds to Toll mRNA and functions in Toll polyadenylation. Wispy lacks RNAbinding domains and is thought to associate to substrates via RNA-binding factors. To identify these factors, we used RNA affinity chromatography using PR as bait. Surprisingly, the RNA interference (RNAi) factor Dicer-2 bound to PR together with Wispy. Dicer-2 interacts with the carboxy-terminal domain of Wispy, containing the nucleotidyl transferase domain. Squelching and depletion experiments indicated that Dicer-2 promotes cytoplasmic polyadenylation and translation of Toll. This function is independent of the RNAi machinery because (i) Ago-2, a partner of Dicer-2 in the RNAi machinery, does not bind to PR, and (ii) Dicer-2 interacts with Wispy in a complex that lacks the RNAi factor R2D2. In addition to Toll, other cytoplasmic polyadenylation substrates bind to Dicer-2. Among these, we identify $r 2 d 2$ mRNA as a novel substrate regulated by Dicer-2 in vitro and in vivo, suggesting the existence of a positive loop to reinforce RNAi in the Drosophila early embryo. Our results reveal a novel function of Dicer-2 in cytoplasmic polyadenylation.

\section{RESULTS}

\section{Wispy is involved in cytoplasmic polyadenylation of Toll mRNA}

To test whether homologs of known cytoplasmic polyadenylation factors could play a role in noncanonical polyadenylation of Toll, we tested their expression in early $(90 \mathrm{~min}$ ) embryos and analyzed their association to Toll mRNA. We focused on Orb2, Wispy, and Symplekin. The two latter factors are readily detected by western blot with specific antibodies (Fig. 1A, input). Because we lacked antibodies against Orb2, we used an Orb2-GFP Drosophila line generated by homologous recombination (Krüttner et al. 2012). Although expression of Orb2 in the early embryo was weak, the protein could be detected after immunoprecipitation (IP) (Fig. 1A, upper panel). We next measured the pres-
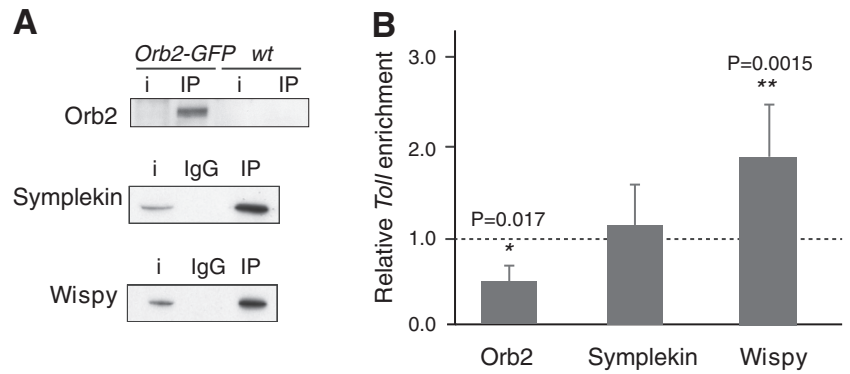

FIGURE 1. Toll mRNA interacts with Wispy. Interactions of Toll mRNA with various cytoplasmic polyadenylation factors was assessed by RIP from Drosophila 90 min embryo extracts. (A) Orb2-GFP was immunoprecipitated with GFP-binder beads from Orb2-GFP, or OrR (wt) embryos used as negative control. Symplekin and Wispy were immunoprecipitated from $\mathrm{OrR}$ embryos, carrying nonspecific IgG as negative control (IgG). Fifteen percent (Symplekin, Wispy) or 50\% (Orb2GFP) of the pellet was loaded to visualize protein; i, 3\%-10\% input extract. (B) The level of Toll mRNA in the pellet was measured by RTqPCR, normalized to the negative control, and represented as enrichment over immunoprecipitation of the nonpolyadenylation substrate sop (dashed line). The plot represents the average of at least three independent experiments. Error bars were calculated as standard deviation, and statistical significance analyzed by unpaired Student's $t$-test $\left({ }^{*}\right) P<$ 0.05 ; (**) $P<0.01 ;\left(^{* * *}\right) P<0.001$. See Supplemental Table S1 for raw data and normalization details.

ence of Toll mRNA in the immunoprecipitates by RT-qPCR, using IgG (in the case of Wispy and Symplekin) or wild-type embryo extracts (in the case of Orb2-GFP) as negative controls. As an additional control, we tested the presence of sop mRNA, an abundant transcript that is not subject to cytoplasmic polyadenylation (Benoit et al. 2008), and expressed the data as enrichment relative to sop. The results showed that Wispy, but not Orb2 or Symplekin, was associated to Toll mRNA (Fig. 1B; see raw data and normalizations in Supplemental Table S1).

To address whether Wispy was involved in cytoplasmic polyadenylation of Toll, we measured the poly(A) tail length of Toll mRNA in embryos from Wispy mutant mothers using the PCR-based poly(A)-test (PAT) assay. Toll poly(A) tail was not elongated in the absence of Wispy (Fig. 2A, cf. lanes 1-3 with 4-6; Cui et al. 2008).

Embryos from wispy mutant mothers do not develop due to primary defects in meiotic progression (Benoit et al. 2008; Cui et al. 2008). A key Wispy target during meiosis is cortex mRNA, which encodes a component of the APC complex required for completion of the meiotic division (Benoit et al. 2008). To assess whether the effect of Wispy on Toll polyadenylation was direct and not due to the lack of Cortex protein, we measured the poly(A) tail length of Toll in cortex mutants, and in wispy mutants in which Cortex levels were rescued using a transgene. The results showed that Toll was polyadenylated in cortex mutants, while polyadenylation was not rescued in wispy mutants expressing Cortex (Fig. 2B, cf. lanes 7-9 with $10-12)$. These results identify Wispy as the poly(A) polymerase required for Toll mRNA cytoplasmic polyadenylation. 
A

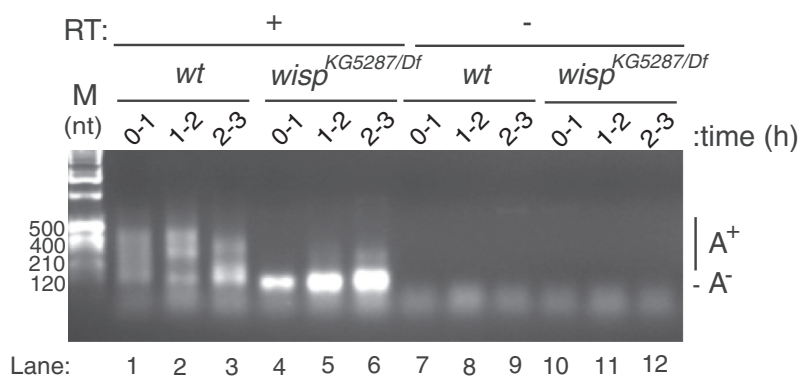

B
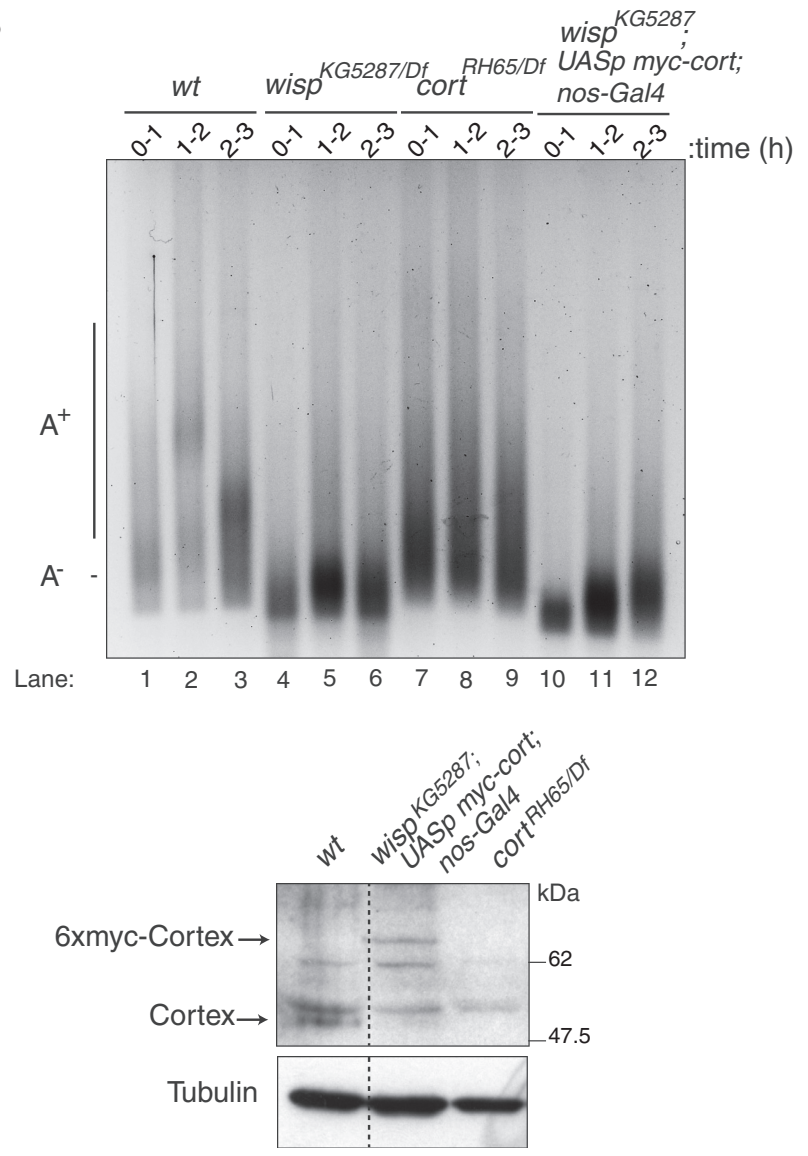

FIGURE 2. Wispy functions in polyadenylation of Toll. (A) Toll poly (A) tail length was assessed by PAT assay of embryos from $w t$ and wispy mutant mothers collected at increasing times after egg laying. wisp ${ }^{K G 5287} / D f$ was wisp ${ }^{K G 5287} / D f(1) R A 47$. RT, reverse transcriptase. (B) As in $A$ following the ePAT protocol. cort $^{R H 65} / D f$ was cort ${ }^{R H 65}$; $D f(2 L)$ exel7027. In wisp ${ }^{K G 5287}$; UASp-myc-cort/nos-Gal4, a Cortex protein containing six myc tags (6xmyc-Cortex) was expressed in the ovarian germline using the UASp-myc-cort transgene and the nos-Gal4 driver. The bottom panel shows a western blot of stage 14 oocytes to visualize Cortex. $\alpha$-Tubulin was used as a loading control. Endogenous Cortex and myc-Cortex proteins were expressed at comparable levels. The dashed line indicates that lanes were separated in the original gel.

\section{Dicer-2 associates with cytoplasmic polyadenylation substrates}

Contrary to nuclear poly(A) polymerases, Wispy lacks RNAbinding domains and associates with mRNA indirectly via
RNA-binding proteins (for review, see Minasaki and Eckmann 2012). In the case of Toll, excess amounts of an RNA fragment including the polyadenylation signals ("polyadenylation region" or PR) competes polyadenylation, indicating that relevant trans-acting factors bind to this region (Fig. 3A; Coll et al. 2010). To identify these factors, we performed RNA affinity chromatography using PR as bait. As control, we used a fragment of PR with no competition capacity (F1, Fig. 3A). The results revealed high-molecularweight factors binding to PR but not to F1 (Fig. 3B, square). These portions of the gel were subjected to proteomics analysis, revealing several PR-binding factors, most prominently Wispy and Dicer-2 (Supplemental Table S2). Independent chromatography experiments followed by western blot confirmed the association of Dicer-2 and Wispy to PR (Fig. 3C).

Binding of Wispy to PR is consistent with its role in Toll mRNA polyadenylation, and suggests that important transacting factors recruit Wispy to this region. Dicer-2 (Dcr-2) has been previously shown to promote the translation of Toll mRNA during immune signaling by binding to its $3^{\prime}$ UTR (Wang et al. 2015), suggesting that Dicer-2 could be the Wispy recruiting factor and that cytoplasmic polyadenylation may underlie the effects of Dicer-2 on translation. In support of this hypothesis, recombinant Dicer-2 binds to PR in electrophoretic mobility shift assays, yielding a complex that is competed by excess PR but not by F1 (Fig. 3D).

Dicer-2 is best known as an RNase III-like enzyme that functions in RNA interference. In Drosophila, there are two Dicer proteins, Dicer-1 and Dicer-2, which function in miRNA and siRNA processing, respectively (Lee et al. 2004). Dicer-2 processes dsRNA precursors into siRNAs, and subsequently associates with the double-stranded RNA-binding protein R2D2 to load siRNAs into Ago-2 leading to formation of siRISC, the effector RNAi complex (Marques et al. 2010). Importantly, Ago-2 did not bind to $\mathrm{PR}$, suggesting RNAi-independent functions of Dicer-2 in cytoplasmic polyadenylation (Fig. 3C).

To test whether endogenous Toll mRNA associated with Dicer-2 in embryos, we performed RNA-immunoprecipitation (RIP) analysis. Dicer-2 was immunoprecipitated using an affinity-purified antibody, and the presence of Toll in the pellet was assessed by RT-PCR. Indeed, Dicer- 2 specifically interacted with Toll mRNA (Fig. 3E). Follow-up RTqPCR experiments indicated that Dicer-2 not only interacted with Toll, but also with other cytoplasmic polyadenylation substrates (bicoid, pgc) (Fig. 3F).

\section{Dicer-2 interacts with Wispy}

We next tested whether Dicer-2 interacts with Wispy. We used extracts from wild type and dicer-2 ${ }^{L 811 f_{s} X}$ null embryos as control (Lee et al. 2004). While these embryos lack Dicer-2, they contain equivalent amounts of Wispy (Fig. 4A, left panel). Immunoprecipitation of Wispy revealed a fraction of Dicer-2 that interacted with Wispy, results that 
A
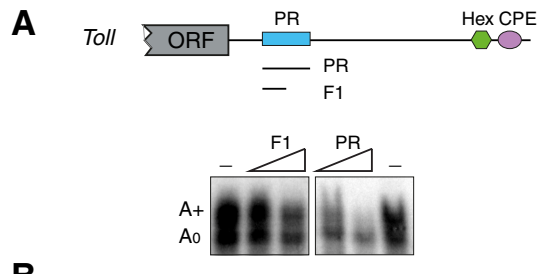

B
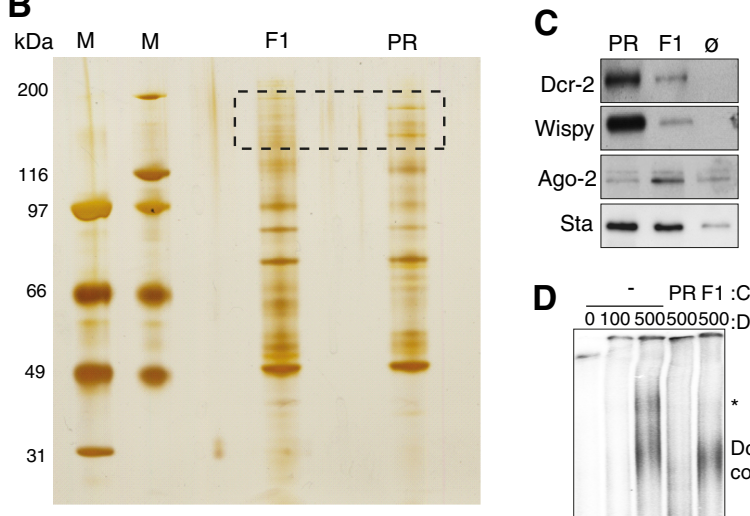

D
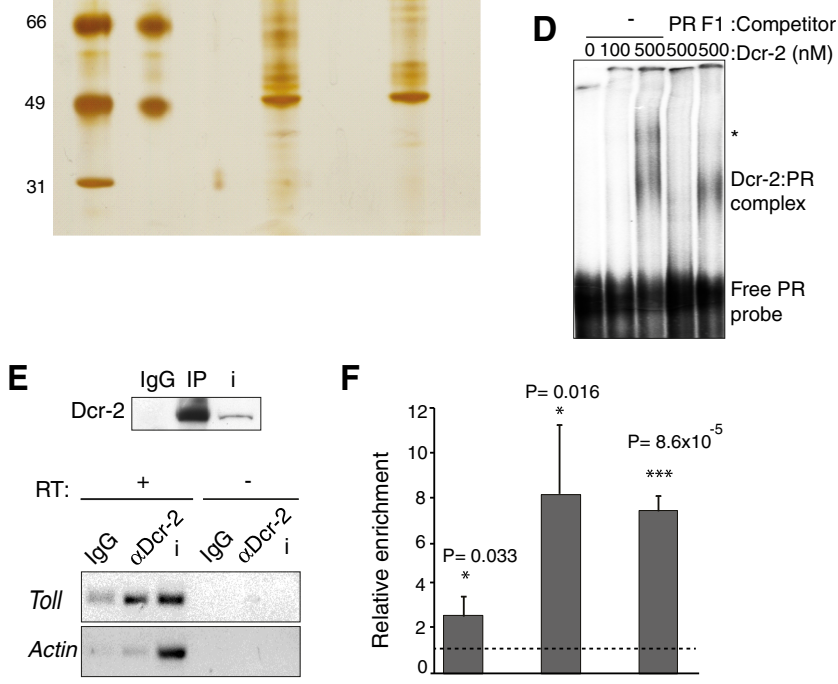

$\mathbf{F}$

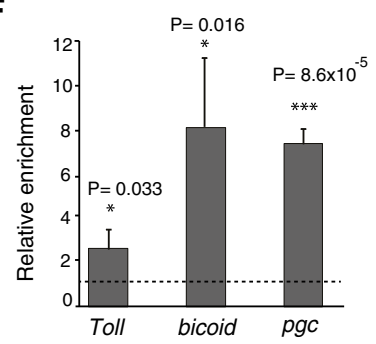

FIGURE 3. Dicer-2 is a potential noncanonical polyadenylation factor. (A) Schematic representation of Toll $3^{\prime}$ UTR depicting functional (PR) and nonfunctional (CPE, Hex) cytoplasmic polyadenylation elements. $\mathrm{PR}$ is a region of $180 \mathrm{nt}$ that, when added in excess, competes polyadenylation of Toll (lower panel). F1 is an $86 \mathrm{nt}$ fragment of PR that lacks competition capacity. Competitors were added at $100 \times$ and $300 \times$ molar excess over Toll RNA. (B) PR and F1 RNAs were used in RNA affinity chromatography, and eluates were separated by SDS-PAGE and silver stained (M, ladder). The region between 116 and $200 \mathrm{kDa}$ (dashed square) was cut and analyzed by mass spectrometry. (C) RNA affinity chromatography followed by western blot confirms the recruitment of Dicer-2 and Wispy to PR, carrying Ago-2 detection as control. The ribosomal protein Stubarista (Sta) was used as loading control. $\varnothing$ indicates chromatography performed with empty beads (no RNA). (D) Dicer-2 binds to PR directly. Recombinant Dicer- 2 was incubated with radiolabeled PR at the indicated concentrations, and complexes were separated by native gel electrophoresis. Excess $(300 \times)$ cold PR or F1 competitor were used to monitor specificity. The position of the free probe and complexes are indicated. The asterisk denotes a nonspecific complex. (E) Dicer-2 was immunoprecipitated from OrR 90 min embryo extracts (upper panel), and the presence of Toll and actin mRNAs in the pellet was tested by semi-quantitative RT-PCR (bottom panel). (RT) Reverse transcriptase. IP with nonspecific IgG was performed as negative control (IgG). i, 3\% input extract. (F) Binding of Dicer-2 to the indicated mRNAs was assessed by RIP followed by RT-qPCR, as indicated in the legend of Figure 1B. Averages with the standard deviation of three independent experiments are represented. Statistical significance was analyzed by unpaired Student's $t$-test $\left({ }^{*}\right) P<0.05$; $\left({ }^{* *}\right) P<0.01$; $\left({ }^{* * *}\right)$ $P<0.001$. See Supplemental Table S1 for raw data and normalization details.
A

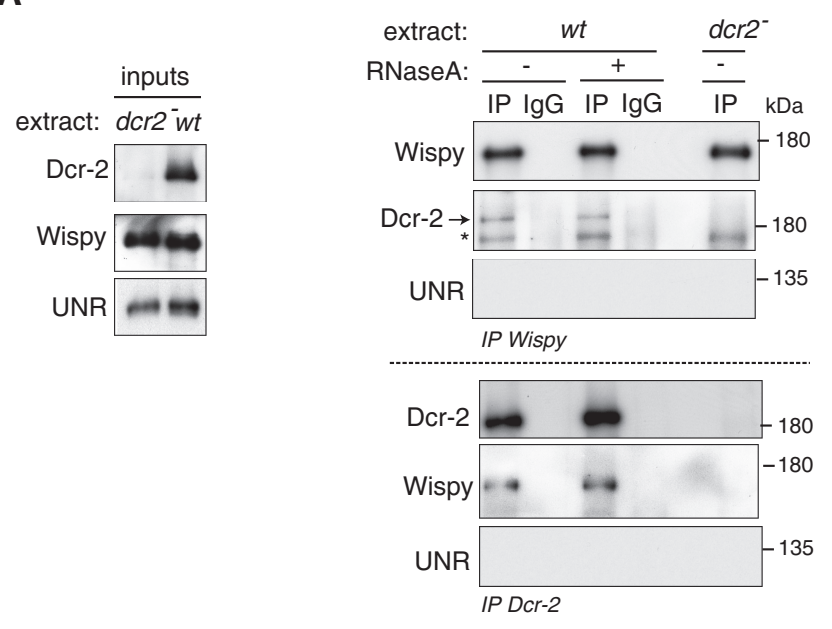

B

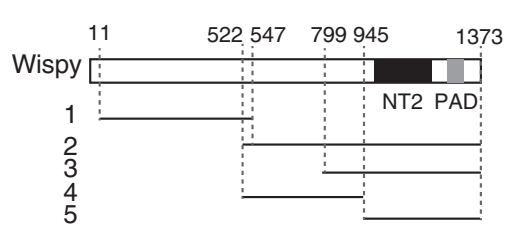

C

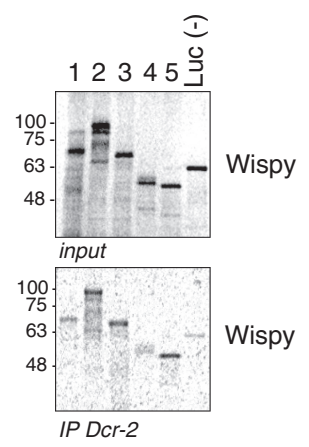

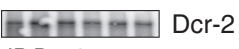
IP DCr-2

FIGURE 4. Dicer-2 interacts with Wispy. (A) Interaction of endogenous Wispy and Dicer-2 was assessed by coimmunoprecipitation from 90 min embryo extracts $(w t)$. dcr- $2^{L 811 f_{s x}}$ null embryo extracts $\left(d c r 2^{-}\right)$or immunoprecipitation with nonspecific IgGs were used as negative controls. The pellets were treated $(+)$ or not $(-)$ with $10 \mu \mathrm{g}$ of RNase A. Inputs are shown on the left. UNR was included as a specificity control. The asterisk denotes a background band. (B) Dicer-2 interacts with the carboxy-terminal domain of Wispy. (Left) Schematic representation of Wispy and the fragments used in the experiment. (NT2) Nucleotidyl-transferase 2 domain; (PAD) poly(A) polymeraseassociated domain. Numbers above Wispy indicate amino acid positions. (Right) Recombinant Dicer-2 was mixed with ${ }^{35}$ S-labeled Wispy fragments $1-5$, and immunoprecipitated using affinity-purified antibodies. Firefly luciferase (Luc) was used as negative control. Wispy inputs $(10 \%)$ and pellets $(30 \%)$ are shown in the upper and middle panels, respectively. The lower panel shows the immunoprecipitated Dcr-2. (C) Ago-2, but not R2D2, interacts with Wispy. Immunoprecipitation of Wispy was performed as in $A$, and the presence of Ago-2, R2D2, and Dicer-2 in the pellet assessed by western blot. Tubulin was used as background control. i, 10\% input. 
were confirmed with the reverse immunoprecipitation (Fig. 4A, right panel). The interaction was specific, as a control abundant RNA-binding protein (UNR) was not coimmunoprecipitated. In addition, the interaction was resistant to digestion with RNase $\mathrm{A}$, suggesting that the two proteins are not simply bridged by RNA. To confirm a direct interaction of Dicer-2 with Wispy, we tested the association of several Wispy fragments produced by in vitro translation with recombinant Dicer-2 using coimmunoprecipitation. The results showed that Wispy fragments containing the carboxy-terminal region, including the nucleotidyl-transferase (NT2) and PAP associated (PAD) domains, coimmunoprecipitated with Dicer-2 (Fig. 4B, fragments 2, 3, and 5), while the aminoterminal and central domains of Wispy (fragments 1 and 4) showed interaction levels similar to the negative control (Firefly luciferase, Luc). We conclude that Dicer-2 interacts with the carboxyterminal domain of Wispy, in a likely direct manner.

To address whether the interaction of Wispy with Dicer-2 occurred in the context of RNAi complexes, we tested whether Wispy interacted with Ago-2 and R2D2 using coimmunoprecipitation in embryo extracts. Although Wispy was found to weakly interact with Ago-2, it did not interact with R2D2 (Fig. 4C). These data support an RNAi-independent function of the Wispy-Dicer-2 complex.

\section{Dicer-2 functions in cytoplasmic polyadenylation}

To test whether Dicer-2 is a cytoplasmic polyadenylation factor, we first performed squelching assays. We added purified, recombinant Dicer-2 to Drosophila extracts and asked whether these could support cytoplasmic polyadenylation. We expected that, when added in excess, Dicer-2 squelches cytoplasmic polyadenylation factors (e.g., Wispy) and inhibits polyadenylation. We found that, indeed, excess Dcr-2 prevented polyadenylation of Toll and Xenopus cyclin B1 (CAT-CycB1) mRNAs, while excess of a control protein (SXL) did not (Fig. 5A).

A

\section{B}
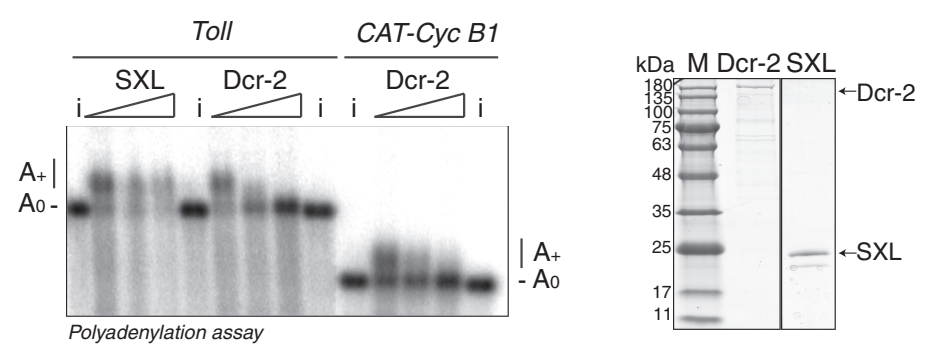

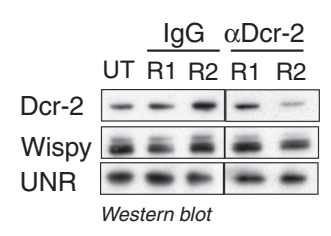

Western blot
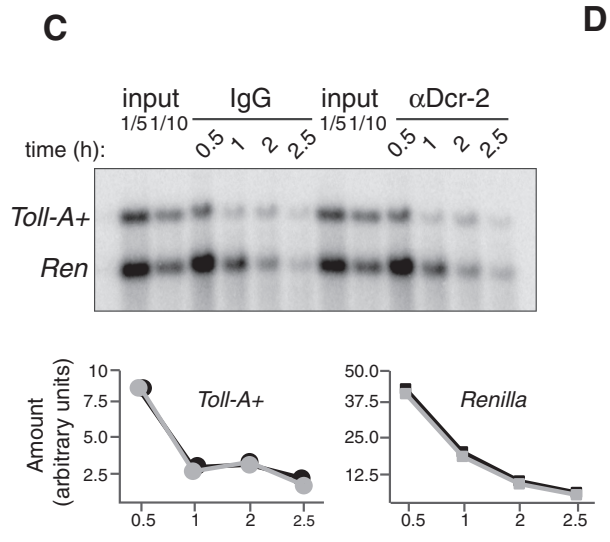

Time (h)

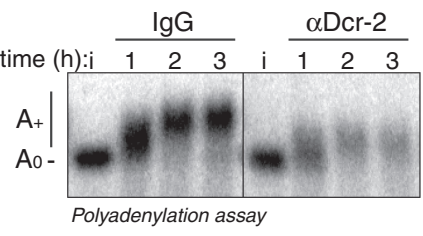

D

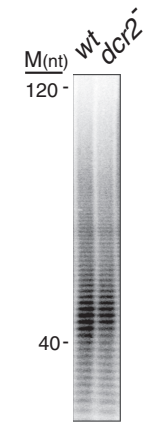

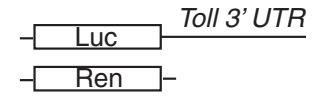

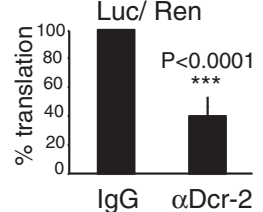

Luc/ Ren

FIGURE 5. Dicer-2 functions in cytoplasmic polyadenylation. (A) Excess Dicer-2 squelches cytoplasmic polyadenylation. Polyadenylation of Toll and CAT-Cyc B1 3' UTRs in the presence of increasing amounts of recombinant Dcr-2 $(0,100$, and $200 \mathrm{nM}$ ). The unrelated protein SXL (amino acids 122-354) was used as negative control. i, 10\% input. The quality of the proteins was assessed by colloidal-blue staining (right panel). (B) Depletion of Dicer-2 reduces Toll polyadenylation and translation. (Left) Efficiency of immunodepletion after one (R1) and two (R2) rounds of depletion. Dicer-2 depletion does not affect Wispy levels. UNR was used as loading control. (Middle) Polyadenylation of radiolabeled Toll 3' UTR in Dicer-2- and mock (IgG)-depleted extracts. The polyadenylation profile at 1,2 , and $3 \mathrm{~h}$ of incubation is shown. (Right) Translational efficiency of Dicer-2- and IgG-depleted extracts. Translation of a Firefly luciferase reporter containing the Toll $3^{\prime}$ UTR was measured. Renilla luciferase mRNA was cotranslated as an internal control. Firefly luciferase was corrected for Renilla expression and referred to the activity in IgG-depleted extracts. Values represent the average \pm STDEV from four independent experiments. Statistical significance was assessed by Student's $t$-test. $(C)$ Depletion of Dicer-2 does not affect Toll deadenylation rate. Cordycepin-labeled Toll-A+ and Renilla mRNAs were coincubated in IgG- and Dicer-2- depleted extracts, and samples collected at $30 \mathrm{~min}, 1,2$, and $2.5 \mathrm{~h}$ of the reaction. RNAs were visualized in a $1.5 \%$ denaturing agarose gel and quantified (bottom); black, mock-depleted extract; gray, Dcr-2-depleted extract. Two dilutions of the input were loaded as reference. $(D)$ Dicer-2 does not affect global polyadenylation states. Assessment of global poly(A) tail lengths in $w t$ and $d c r-2$ null embryos.

We next depleted Dcr-2 from extracts using affinity-purified antibodies. Typically, two to three rounds of depletion were necessary to reduce the amount of Dicer-2 (Fig. 5B, 
left panel). The amount of Wispy in depleted and control mock-depleted extracts was equivalent (Fig. 5B, left panel). We then tested polyadenylation of exogenously added radiolabeled Toll 3' UTR in these extracts. We found that both polyadenylation and stability of Toll were affected (Fig. 5B, middle panel). Consistent with these defects, translation of a reporter containing the Toll $3^{\prime}$ UTR decreased in Dicer-2depleted extracts (Fig. 5B, right panel). The stability defect is likely a direct consequence of reduced poly(A) tail length, as the poly(A) tail promotes not only translation but also mRNA stability (Barckmann and Simonelig 2013; Wahle and Winkler 2013). The reduced poly(A) tails of Toll in Dicer-2-depleted extracts are consistent with two possible scenarios: (i) Dicer-2 promotes cytoplasmic polyadenylation or, (ii) Dicer-2 inhibits deadenylation. To distinguish between these possibilities, we uncoupled polyadenylation from deadenylation using cordycepin ( $3^{\prime}$ deoxyadenosine). Addition of cordycepin to the $3^{\prime}$ end of a transcript prevents further adenylation but not deadenylation. We therefore added radiolabeled cordycepin to the $3^{\prime}$ end of a polyadenylated Toll transcript and monitored the fate of this mRNA in mock- and Dicer-2-depleted extracts. As an internal control, Toll was coincubated with cordycepin-labeled Renilla mRNA, which should not show changes upon Dicer-2 depletion. We reasoned that, if Dicer-2 inhibits deadenylation, the rate of cordycepin disappearance from Toll should be higher in Dicer2-depleted extracts. However, we found equivalent cordycepin signals along time for mock- and Dicer-2-depleted extracts (Fig. 5C). We conclude that Dicer-2 behaves as a cytoplasmic polyadenylation factor. This function should be restricted to a specific population of mRNAs, because the bulk poly(A) length of mRNAs remains constant in dicer-2 null embryos (Fig. 5D).

\section{Dicer-2 promotes the cytoplasmic polyadenylation of $r 2 \mathrm{~d} 2 \mathrm{mRNA}$}

It has been reported that dicer-2 null embryos lack R2D2 (Fig. 6A; Liu et al. 2006; Lim et al. 2008). This defect has been attributed to Dicer-2 promoting the stability of R2D2 protein, although this possibility has not been directly tested (Liu et al. 2006). Ectopic R2D2 can be efficiently expressed in Dicer-2depleted cells, indicating alternative regulatory mechanisms (Nishida et al. 2013). Given the role of Dicer-2 as a cytoplasmic polyadenylation factor, we tested whether Dicer- 2 could promote the cytoplasmic polyadenylation and translation of $r 2 d 2$ mRNA. In agreement with an RNA-related function of this protein, Dicer-2 binds to $r 2 \mathrm{~d} 2 \mathrm{mRNA}$ in Drosophila embryos (Fig. 6B). In addition, a reporter containing the $3^{\prime}$ UTR of $r 2 d 2$ was translated at higher levels than a reporter without this UTR in vitro, and at levels similar to a polyadenylated reporter (Fig. 6C). Importantly, addition of cordycepin to the $3^{\prime}$ end of the $r 2 d 2$ reporter inhibited translation, indicating that translation of $r 2 \mathrm{~d} 2 \mathrm{mRNA}$ is driven by cytoplasmic polyadenylation (Fig. 6C). Indeed, the $r 2 d 23^{\prime}$ UTR
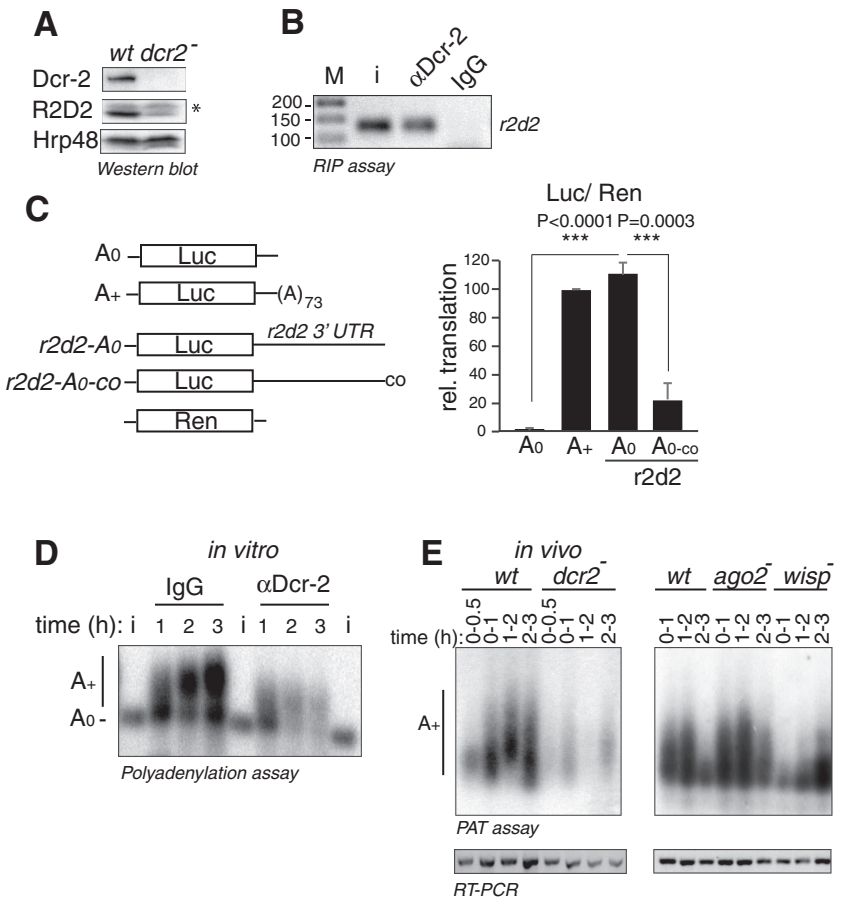

FIGURE 6. Dicer- 2 promotes polyadenylation of $r 2 d 2$ mRNA. $(A)$ R2D2 protein levels decrease in $d c r-2$ null flies. Protein levels were assessed by western blot. Hrp48 was used as loading control. The asterisk denotes a nonspecific band. (B) Dicer-2 binds to endogenous $r 2 d 2$ mRNA. Dicer-2 was immunoprecipitated from 90 min embryo extracts and the presence of $r 2 d 2$ mRNA in the pellet assessed by RT-PCR. M, marker; i, input. (C) $r 2 d 23^{\prime}$ UTR promotes translation in a polyadenylation-dependent manner. The translation efficiency of a luciferase reporter containing the $3^{\prime}$ UTR of $r 2 d 2\left(r 2 d 2-A_{0}\right)$ was compared with reporters lacking $r 2 d 2$ and either containing $(A+)$ or not $\left(A_{0}\right)$ a poly $(\mathrm{A})$ tail. An $r 2 d 2$ construct with cordycepin at its $3^{\prime}$ end was included $\left(r 2 d 2-A_{0}-c o\right)$. Translation was assessed as described in the legend of Figure $5 \mathrm{~B}$. The plot represents the average \pm STDEV of three experiments. Statistical significance was analyzed by unpaired Student's $t$-test. Cordycepin prevents translation of $r 2 d 2$, suggesting that the reporter acquires a poly(A) tail during the reaction. (D) $r 2 d 23^{\prime}$ UTR is polyadenylated in embryo extracts, and Dicer- 2 depletion reduces the polyadenylation efficiency. Assays were performed as described in the legend of Figure 2B. (E) Polyadenylation of $r 2 d 2$ mRNA is reduced in $d c r-2$ and wispy, but not in ago 2 null embryos. PAT assays were performed in $w t\left(w^{1118}\right), d c r-2^{L 811 f_{s} X}, w i s p^{K G 5287 / D f}$, and ago $2^{414}$ embryos as indicated in the legend of Figure 2A. To increase the sensitivity of the assay in $d c r-2$ extracts, amplified products were visualized by Southern blot using an $r 2 d 2$-specific probe (upper left panel). To ensure that $r 2 d 2$ mRNA was present in null embryos, semi-quantitative PCR with oligonucleotides detecting $r 2 d 2$ was performed from the same RNA samples used for the PAT assay (lower panels).

was polyadenylated in embryo extracts, and this polyadenylation dramatically decreased in the absence of Dicer-2 (Fig. $6 \mathrm{D})$. Consistent with these in vitro results, endogenous $r 2 d 2$ mRNA was polyadenylated in vivo, and the extent of polyadenylation decreased in $d c r-2$ or wispy null embryos, while it remained unaffected in ago2 null embryos (Fig. $6 \mathrm{E})$. These results indicate that Dicer- 2 regulates $r 2 d 2$ expression at the level of cytoplasmic polyadenylation in an RNAiindependent manner. 


\section{DISCUSSION}

The mechanisms governing cytoplasmic polyadenylation in early embryos are poorly understood. We have previously shown evidence for a noncanonical machinery that functions independently of the CPE and the Hex in Drosophila embryos (Coll et al. 2010). Here we identify Dicer-2 and Wispy as components of this machinery. These results uncover a novel function of Dicer-2 in mRNA activation through cytoplasmic polyadenylation.

Cytoplasmic poly(A) polymerases are thought to be recruited to the $3^{\prime}$ UTRs of substrate mRNAs by RNA-binding factors. This is best illustrated in C. elegans, where the polymerase GLD-2 can be recruited to the mRNA by GLD-3, RNP-8 or other RNA-binding proteins, contributing to a major mechanism to control cell identity during early embryogenesis (Kim et al. 2009; Elewa et al. 2015). During Xenopus oocyte maturation, GLD-2 is recruited to the mRNA by the concerted action of CPEB, CPSF, and Symplekin (Barnard et al. 2004). Alternative proteins for recruitment of cytoplasmic poly(A) polymerases and/or efficient polyadenylation have been described, including aCP2 in Xenopus embryos or QKI-7 in somatic mammalian cells (Vishnu et al. 2011; Yamagishi et al. 2016). However, these factors rely on the Hex-and by inference on CPSF-for efficient polyadenylation. The noncanonical machinery that operates in Drosophila embryos is different in that it is totally independent of the classical polyadenylation elements (Coll et al. 2010). This machinery contains Dicer-2, a Wispy-binding factor (Figs. 3, 4). The Dicer-2 polyadenylation machinery is important to achieve appropriate levels of Toll and R2D2 during early development (Figs. 5, 6; Coll et al. 2010). As R2D2 cooperates with Dicer-2 during RNAi, stimulation of $r 2 d 2$ mRNA translation by Dicer- 2 may enforce RNAi in the early embryo.

Three lines of evidence are consistent with an RNAi-independent function of Dicer-2 in cytoplasmic polyadenylation. First, Dicer-2 associates with PR in the absence of Ago-2 (Fig. 3; Supplemental Table S2). Second, Wispy interacts with Dicer-2, but not with R2D2 (Fig. 4). Third, we detect no processing of Toll or $r 2 d 2 \mathrm{mRNAs}$ during cytoplasmic polyadenylation (data not shown). Binding of Drosophila Dicer-2 to these transcripts without apparent processing is consistent with previous findings showing that human and C. elegans Dicer can bind to mRNA in a "passive" manner (RybakWolf et al. 2014). Passive sites are characterized by stem-loops with short stems, where Dicer binding is detected at the loop region. We have performed SHAPE structural analysis of the Toll $\mathrm{PR}$ region and indeed find three such stem-loops (Supplemental Fig. 1). Binding of recombinant Dicer-2 to PR occurs at high protein concentrations $(500 \mathrm{nM})$, suggesting that other proteins or additional Toll RNA elements contribute to efficient Dicer-2 binding to this region. The proteins in Supplemental Table S2 represent potential candidates. Furthermore, consistent with shared polyadenylation factors which are distinct from those operating in the canonical process, Toll polyadenylation is competed by excess of $r 2 d 2$ RNA and vice versa, while polyadenylation of none of these transcripts is competed by CycB1 RNA (Supplemental Fig. 2).

A previous report showed that Dicer-2 and Ago-2 can regulate poly(A) tail lengths in Drosophila S2 cells (Siomi et al. 2005). Our results differ from this report in several important aspects. First, poly(A) tail regulation in S2 cells was linked to the RNAi machinery and to the capacity of Dicer-2 to prevent deadenylation by the CCR4/NOT/CAF1 complex. We show here that, in embryos, Dicer- 2 regulates cytoplasmic polyadenylation in an RNAi- and deadenylation-independent fashion. Second, Siomi found that poly(A) tail shortening upon Dicer-2 depletion correlates with increased protein levels; however, we find a translation-promoting role of Dicer- 2 . Third, in S2 cells Dicer- 2 maintained the poly(A) tail of a reporter EGFP transgene without apparent specificity signals, but did not affect the poly(A) tail of a transiently expressed reporter, and effects on endogenous transcripts were not reported. We find that, in embryos, Dicer-2 functions on both endogenous and exogenous transcripts containing signals for cytoplasmic polyadenylation. Finally, we have found that SL2 cells express no Wispy and rather low levels of other cytoplasmic poly(A) polymerases (Supplemental Fig. 3). Altogether, these data suggest that different phenomena are observed in cultured cells and embryos.

Our data are in agreement with recent findings of an RNAi-independent function of Dicer- 2 in Toll immune signaling, where Dicer- 2 was found to increase the translation of Toll mRNA and promote resistance to fungal infection (Wang et al. 2015). We provide here a molecular mechanism for translational control by Dicer- 2 in embryos. In addition to the reported increased sensitivity to infection, we find that the loss of Dicer- 2 causes a dramatic reduction in fertility: Males are sterile while females lay 18\% eggs compared with wild-type flies (Table 1). These data suggest that, in

\begin{tabular}{lccr} 
TABLE 1. Fertility of $d c r 2^{L 811 f s X}$ flies & \\
\hline Cross (male $\times$ female) & No. of eggs laid ${ }^{a}$ & \% Eggs laid (relative to $w t)$ & \% Eggs developing after 3 d \\
\hline$w^{1118} \times w^{1118}$ & 2321 & 100 & 93.7 \\
$d c r 2^{L 811 f s X} \times w^{1118}$ & 601 & 25.9 & 5.6 \\
$w^{1118} \times d c r 2^{L 811 f s X}$ & 415 & 17.9 & 76.8 \\
\hline
\end{tabular}

${ }^{\mathrm{a}}$ Total number of eggs laid during a period of $24 \mathrm{~h}$ in three independent experiments. 
addition to Toll and $r 2 d 2$, Dicer-2 might be important for the expression of other transcripts. Furthermore, $d c r-2$ mutants have been shown to exhibit reduced life-span and hypersensitivity to a whole array of stress conditions including oxidative, endoplasmic reticulum, starvation and cold stress (Lim et al. 2011). Intriguingly, reductions-rather than increases-in protein and mRNA abundance were most often detected under these conditions, raising the possibility that the mechanism we describe here for Dicer-2 in mRNA activation can be extended to adult flies.

Very recently, another small RNA factor was reported to interact with Wispy. Aubergine, an Argonaute protein of the Piwi-interacting RNA pathway, interacts with a central region of Wispy and promotes cytoplasmic polyadenylation and stabilization of mRNAs involved in germ cell specification and development at the posterior pole of the embryo (Dufourt et al. 2017). This highlights the interconnection between small RNA factors and the cytoplasmic polyadenylation machinery.

In addition to Wispy, other poly(A) polymerases are expressed in early embryos (Supplemental Fig. 3). Together with the variety of RNA-binding factors, this increases the diversity of potential polyadenylation machineries exponentially. Identifying these machineries, their conservation, their substrates and relevance in development and cell homeostasis are important questions for future research.

\section{MATERIALS AND METHODS}

\section{Flies}

OrR and $w^{1118}$ were used as wild-type flies. The following mutant or transgenic stocks were used: Orb2-GFP (kindly provided by Dr. Krystyna Keleman), w; Dcr2 $2^{L 811 f_{s} X} / C y O$, amos ${ }^{\text {Roi-1 }}$, wisp ${ }^{K G 5287}$ (a wisp null allele) and $D f(1) R A 47$ that overlaps wisp (Benoit et al. 2008), cort ${ }^{R H 65}$ and UASp-myc-cortex (Pesin and Orr-Weaver 2007), $D f(2 L)$ exel7027 that overlaps the cortex gene (Bloomington Stock Center), ago $2^{414}$ (Okamura et al. 2004), and nos-Gal4 (Rørth 1998). Flies were maintained on standard food at $25^{\circ} \mathrm{C}$.

To produce Dicer- 2 null embryo extracts, $w ; D c r 2^{L 811 f_{s} X}$ homozygous females were crossed with $w^{1118}$ males and embryos were collected at $90 \mathrm{~min}$ after egg laying. To ensure uniform staging of embryos, trays were exchanged three times before the final embryo collection. As a control, the same procedure using $w^{1118}$ females was followed. wisp and cortex mutant females were also crossed with $w^{1118}$ males.

\section{Protein expression}

Dcr-2 was expressed in Baculovirus-infected Sf9 cells from a pFastBac-HisDcr-2His construct kindly provided by Dr. Quinghua Liu, following the recommendations of the Bac-to-Bac Baculovirus Expression System Manual (Invitrogen) for expression, and the protocol described by Ye and Liu (2008) for purification.

SXL (amino acids 122-354) was expressed in E. coli as a Histagged fusion and purified as previously described (Hennig et al. 2014). Briefly, SXL expression was induced with $1 \mathrm{mM}$ IPTG for
$3 \mathrm{~h}$ at $37^{\circ} \mathrm{C}$, and cell pellets were resuspended in lysis buffer [500 $\mathrm{mM} \mathrm{NaCl}, 50 \mathrm{mM} \mathrm{NaH}{ }_{2}(\mathrm{PO})_{4} \mathrm{pH} 8.0,10 \mathrm{mM}$ imidazole, $1 \times$ Roche protease inhibitors mix]. Cells were sheared, centrifuged, and the SXL protein in the supernatant purified using Ni-NTA columns. All proteins were dialyzed against buffer D (20 mM HEPES pH 8.0, 20\% glycerol, 1 mM DTT, 0.01\% NP-40, 0.2 mM EDTA).

Wispy fragments were expressed as ${ }^{35}$ S-labeled proteins in RRL and TNT in vitro translation systems following the instructions from the manufacturer.

\section{Antibodies}

Antibodies against Dicer-2 and R2D2 were originally provided by Dr. Qinghua Liu (Liu et al. 2003). We also raised anti-Dicer-2 polyclonal antibodies against the first 151 aa of Dicer-2 in rabbits. These antibodies were affinity-purified in a HiTrap NHS-activated HP column (GE Healthcare) coupled with His-Dicer-2(1-257)-MBP protein. Antibodies against aa 1-300 of Ago2 and full-length stubarista (Sta) were generated in rabbits. Antibodies against Symplekin (Sullivan et al. 2009), Wispy (Cui et al. 2008), and Cortex (Pesin and Orr-Weaver 2007) were kindly provided by Drs. Bill Marzluff, Mariana Wolfner, and Terry Orr-Weaver, respectively. Anti-UNR antibodies were previously described (Abaza et al. 2006). Anti-GFP (Invitrogen, A6455) and mouse anti- $\alpha$ Tubulin (T5168, Sigma) were provided commercially. These antibodies were used in western blot at the following dilutions: anti-Dcr-2 1:500 and 1:2000, antiAgo-2 1:1000, anti-Sta 1:2000, anti-Symplekin 1:1000, anti-Wispy 1:500 and 1:2000, anti-GFP 1:1000, anti-Cortex 1:2000, anti-UNR 1:2000, anti-Hrp48 1:10,000, anti-aTubulin 1:20,000.

\section{Plasmids}

DNA constructs for the generation of Toll 3' UTR, Luc-Toll, Luc-A+, $L u c-A_{0}$, and $C A T-C y c B 1$ mRNAs were previously described (de Moor and Richter 1999; Coll et al. 2010). To generate the $r 2 d 2$ reporter, the $3^{\prime}$ UTR of $r 2 d 2$ mRNA was amplified by RT-PCR from $90 \mathrm{~min}$ embryo extracts using oligonucleotides r2d2-f-SmaI ( $5^{\prime}$ TCCCCCGGGTGCGTATAACATTTATTCAAC) and r2d2-r-SalI (5'-ACGCGTCGACTTTATTTATTTTAGACTGAAA), and cloned into the SmaI/SalI sites of pBSK. This fragment was also cloned downstream from the Firefly luciferase ORF in pBSK to obtain $\mathrm{r} 2 \mathrm{~d} 2-\mathrm{A}_{0}$. Wispy fragments $1-3$ (Fig. $4 \mathrm{~B}$ ) were cloned into pCSH3 (Joly et al. 2013), and fragments 4 and 5 into pGEMT. The fragments were engineered to contain HA-tags at the amino terminus. Fragment 5, in addition, contains a Flag-tag at the $\mathrm{C}$ terminus. All constructs were verified by sequencing.

\section{In vitro transcription}

mRNAs were synthesized as described previously (Gebauer et al. 1999). RNAs either lacked or contained a poly(A) tail of 73 residues, as indicated. mRNAs used for translation contained a ${ }^{7 \mathrm{~m}} \mathrm{GpppG}$ cap, and RNAs used for competition contained an ApppG cap. RNAs used for polyadenylation were trace-labeled with $a^{32} \mathrm{P}$-UTP and contained an ${ }^{7 \mathrm{~m}} \mathrm{GpppG}$ cap.

Biotinylated transcripts used in affinity chromatography assays were synthesized using the Megashort Script kit (Invitrogen) following the manufacturer's instructions. In these reactions, bio-CTP was added at a ratio of 1:1 compared with CTP. These RNAs contained 
an ApppG cap. The quality and quantity of all RNAs were monitored by visualization in agarose gels.

\section{Labeling with cordycepin}

Labeling with radioactive cordycepin was used to determine global poly(A) tail lengths, or to prevent polyadenylation of reporters. Labeling was performed with yeast PAP (kindly provided by Drs. Elmar Wahle and Uwe Kühn) as follows. Total RNA from Drosophila $90 \mathrm{~min}$ embryos $(1.5 \mu \mathrm{g})$ or in vitro synthesized Toll-A+ and Renilla mRNAs $(0.03 \mathrm{pmol})$ were incubated with $200 \mathrm{ng}$ yeast PAP in a reaction of $20 \mu \mathrm{L}$ containing $20 \mathrm{mM}$ TRIS$\mathrm{HCl} \mathrm{pH} \mathrm{7.0,} 50 \mathrm{mM} \mathrm{KCl}, 10 \%$ glycerol, $1 \mathrm{mM}$ DTT, $0.7 \mathrm{mM}$ $\mathrm{Mn}-\mathrm{II}-\mathrm{Cl}_{2}, 40 \mathrm{U}$ RNasin and $2 \mu \mathrm{L}{ }^{32} \alpha \mathrm{P}$-cordycepin (PerkinElmer NEG026250UC). After $30 \mathrm{~min}$ incubation at $30^{\circ} \mathrm{C}, 10 \mu \mathrm{g}$ yeast tRNA was added as carrier, and RNAs were treated with phenolchloroform and precipitated.

For determination of global poly(A) tail length, $10^{5} \mathrm{cpm}$ were treated with $2 \mu \mathrm{g}$ RNase A and $50 \mathrm{U}$ RNase T1 in a final volume of $80 \mu \mathrm{L}$ containing $200 \mathrm{mM} \mathrm{NaCl}$ and $10 \mathrm{mM}$ TRIS-HCl $\mathrm{pH}$ 8.0, for $45 \mathrm{~min}$ at $30^{\circ} \mathrm{C}$. The reaction was stopped by adding $20 \mu \mathrm{L}$ of a mix containing $10 \mu \mathrm{g}$ proteinase $\mathrm{K}, 5 \mu \mathrm{g}$ glycogen, 5\% SDS and $50 \mathrm{mM}$ EDTA, and incubating for $30 \mathrm{~min}$ at $37^{\circ} \mathrm{C}$. RNAs were then precipitated (without phenol extraction) and separated in a $12 \%$ acrylamide-urea sequencing gel.

\section{Cytoplasmic polyadenylation and translation assays}

Cytoplasmic extracts from staged 90 min embryos were obtained as previously described (Gebauer et al. 1999). Polyadenylation and translation assays in these extracts were performed as previously described, without the addition of tRNA (Gebauer et al. 1999). Typically, 0.01 pmol of substrate mRNA were used per $12.5 \mu \mathrm{L}$ reaction. In translation reactions, Renilla mRNA was cotranslated as an internal control. Luciferase activity was measured using the Dual Luciferase Assay System (Promega), and Firefly luciferase values were corrected for Renilla expression. In polyadenylation reactions, radiolabeled RNAs were used and visualized by separation in $1 \%$ denaturing agarose gels.

\section{PAT assays}

PAT assays were performed as previously described (Coll et al. 2010), or using the ePAT method (Jänicke et al. 2012) for Figure 2B. Oligos for amplification of Toll and $r 2 d 2$ poly(A) tails were: PAT-r2d2-f 5'TTTGCCTTTAAAAGGAATGCTAGTAATC3'; PAT-Toll-f 5'GG TACCTACAGATTTATGCAGAC3'; and oligo(dT)-anchor $5^{\prime} \mathrm{GC}$ GAGCTCCGCGGCCGCGTTTTTTTTTTTT3'. To increase the sensitivity and test the specificity of $r 2 d 2$ PAT assays, PAT products were subjected to Southern blot analysis using a $r 2 d 2$-specific probe. To ensure that null embryos contained $r 2 d 2$ mRNA, $r 2 d 2$ was amplified by semi-quantitative PCR from the same RNA samples used in PAT assays.

\section{Dicer-2 immunodepletion}

Dicer-2 was immunodepleted from $1 \mathrm{mg}$ embryo extract by two consecutive incubations with $100 \mu \mathrm{L}$ protein A Dynabeads containing af- finity purified anti-Dicer-2 antibody. Briefly, $100 \mu \mathrm{L}$ beads were washed three times with five volumes of wash buffer $(10 \mathrm{mM}$ HEPES pH 8.0, 8\% glycerol) and blocked with $1 \mathrm{mg}$ embryo extract for $1 \mathrm{~h}$ at room temperature. Beads were then washed $(4 \times 5 \mathrm{vol}$ wash buffer) and $20 \mu \mathrm{g}$ of affinity-purified anti-Dicer-2 antibody or rabbit IgG were added. The suspension was incubated for $1 \mathrm{~h}$ at room temperature, and the beads were washed $(5 \times 5$ vol wash buffer $)$ and all liquid removed. One milligram of embryo extract were then added, and the mix incubated on ice for $30 \mathrm{~min}$ with occasional stirring. The extract was collected, added to fresh beads, and the process repeated. Depletion was confirmed by western blotting.

\section{Immunoprecipitation (IP) and RNA immunoprecipitation (RIP)}

For standard IP, $150 \mu \mathrm{g}$ of Drosophila 90 min embryo extract were incubated with $25 \mu \mathrm{L}$ of Protein A Dynabeads (Invitrogen) bound to the appropriate antibody in a final volume of $100 \mu \mathrm{L}$ of $1 \times$ NET buffer (50 mM TRIS-HCl pH 7.5, $150 \mathrm{mM} \mathrm{NaCl}, 0.1 \%$ NP40, $1 \mathrm{mM}$ EDTA). After $1 \mathrm{~h}$ of incubation at $4^{\circ} \mathrm{C}$, beads were washed twice with 10 bead volumes of $1 \times \mathrm{NET}$, and treated or not with $10 \mu \mathrm{g}$ RNase A for $30 \mathrm{~min}$ at room temperature. Beads were then washed with 10 vol $1 \times$ NET and the proteins extracted with SDS loading buffer.

For RIP, $500 \mu \mathrm{g}$ of 90 min embryo extract were used in conditions similar to IP, except that the incubation was carried at $25^{\circ} \mathrm{C}$, and five washes were performed with $5 \times$ bead volumes of $1 \times$ NET buffer. Proteins recovered from $15 \%$ of the beads were resolved by SDSPAGE and $85 \%$ of the beads were used for RNA extraction. For Orb2-GFP RIP, $5 \mathrm{mg}$ of embryo extract were incubated with 30 $\mu \mathrm{L}$ GFP-Trap_M beads (Chromotek) for $2 \mathrm{~h}$ at $4^{\circ} \mathrm{C}$ and the immunoprecipitation performed following the manufacturer's instructions; half of the sample was used to visualize protein by SDSPAGE, while the remaining half was used for RNA extraction. RNA was extracted from the beads using TRIzol (Invitrogen) after addition of $5 \mu \mathrm{g}$ tRNA as carrier. RNA from input samples was processed in parallel, and its quality assessed in agarose gels.

\section{RT-qPCR and semi-quantitative PCR}

RNA was treated with Turbo DNase (Ambion) in a final volume of $25 \mu \mathrm{L}$. Five microliters were then used for reverse-transcription with SuperScript II (Invitrogen) using random primers and oligo(dT) following the instructions of the manufacturer. Similar reactions were assembled without Superscript II as negative controls. cDNA was amplified by either semi-quantitative PCR with Taq DNA polymerase (PCR Master Mix Promega) or qPCR with SYBR Green (Applied Biosystems). Typically, $1 \mu \mathrm{L}$ of a (1:3) dilution of the cDNA was used for qPCR while $5 \mu \mathrm{L}$ were used for semi-quantitative PCR. The quality and sequences of oligonucleotides used for amplification of Toll, sop, bicoid, and $p g c$ are detailed in Supplemental Table S1. Oligos for qPCR of $r 2 d 2$ are as follows: r2d2-f $5^{\prime}$ AATGCTGGCCTTAA TCTCCA3' and r2d2-r 5'TGCCTCCAATTCCTCCATAG3'.

\section{RNA affinity chromatography}

Thirty microliters of streptavidin Dyneabeads (Life Technologies) were equilibrated in TCE buffer $(16.8 \mathrm{mM}$ creatine phosphate, 
$0.08 \mu \mathrm{g} / \mu \mathrm{L}$ creatine kinase, $24 \mathrm{mM}$ HEPES $\mathrm{pH}$ 7.5, $0.6 \mathrm{mM}$ magnesium acetate, and $80 \mathrm{mM}$ potassium acetate), and blocked for $5 \mathrm{~min}$ with $100 \mathrm{ng} / \mu \mathrm{L}$ tRNA at room temperature. Thirty three picomoles of biotinylated RNA and $10 \mathrm{U}$ RNasin were added to the beads and incubated under rotation for $1 \mathrm{~h}$ at $4^{\circ} \mathrm{C}$. The supernatant was removed and $2 \mathrm{mg}$ Drosophila embryo extract (previously clarified by centrifugation at $13.000 \mathrm{rpm}$ for $15 \mathrm{~min}$ at $4^{\circ} \mathrm{C}$ ) were added, together with $320 \mathrm{ng} / \mu \mathrm{L}$ heparin and protease inhibitors (Roche). The mix was incubated for $30 \mathrm{~min}$ at room temperature under rotation. Beads were then washed five times with 1 volume of TCE supplemented with $0.1 \%$ Triton $\mathrm{X}-100,320 \mathrm{ng} / \mu \mathrm{L}$ heparin and $10 \%$ glycerol. RNA-bound proteins were eluted from the beads by incubation with $20 \mu \mathrm{L}$ of elution buffer ( $10 \mathrm{mM}$ Tris- $\mathrm{HCl} \mathrm{pH} \mathrm{7.2,} 1 \mathrm{mM} \mathrm{MgCl}_{2}$, $40 \mathrm{mM} \mathrm{NaCl}, 2 \mu \mathrm{L}$ RNase cocktail from Ambion AM2286) for 30 min at $37^{\circ} \mathrm{C}$. Samples were separated on precasted $4 \%-12 \%$ gradient gels (Invitrogen) and silver-stained. Bands of interest were sliced from the gel and identified by mass spectrometry.

\section{Mass spectrometry}

Gel bands were destained and subsequently digested with $0.1 \mu \mathrm{g}$ trypsin overnight at $37^{\circ} \mathrm{C}$. After digestion, peptides were extracted, acidified with formic acid and desalted with Empore C18 columns prior to LC-MS/MS analysis. Samples were analyzed using a LTQOrbitrap XL mass spectrometer (Thermo Fisher Scientific) coupled to an Agilent Technologies 1200 Series. All data were acquired with Xcalibur software v2.2. The Proteome Discoverer software suite (v1.3.0.339, Thermo Fisher Scientific) and the Mascot search engine (v2.3, Matrix Science) were used for peptide identification. The data were searched against an in-house generated database containing all Drosophila proteins from NCBInr database (\# entries 215.956). A precursor ion mass tolerance of $7 \mathrm{ppm}$ at the MS1 level was used, and up to three miscleavages for trypsin were allowed. The fragment ion mass tolerance was set to $0.5 \mathrm{Da}$. Oxidation of methionine and protein acetylation at the $\mathrm{N}$ terminal were set as variable modifications. Peptides have been filtered using a Mascot Ion Score of 20.

\section{Gel mobility shift assay (EMSA)}

EMSA was performed as previously described (Abaza et al. 2006). Briefly, ${ }^{32} \mathrm{P}$-labeled PR was incubated with recombinant Dicer-2 in a final volume of $20 \mu \mathrm{L}$ containing $3 \mu \mathrm{g}$ tRNA, $100 \mathrm{mM} \mathrm{KCl}$, $20 \mathrm{mM}$ HEPES pH 8.0, 20\% glycerol, $1 \mathrm{mM}$ DTT, 0.01\% NP-40, and $0.2 \mathrm{mM}$ EDTA. Where indicated, competitor cold PR or F1 RNAs were added at $300 \times$ molar excess. After $30 \mathrm{~min}$ incubation on ice, complexes were separated in a native $4 \%$ acrylamide gel.

\section{SHAPE}

Secondary RNA structure was determined using selective 2' -hydroxyl-acylation analyzed by primer extension (SHAPE) (Wilkinson et al. 2006). Primer extension reactions were assembled with RNA templates previously treated with NMIA (13 mM or $26 \mathrm{mM}$ NMIA for PR and Toll $3^{\prime}$ UTR, respectively, treated for $45 \mathrm{~min}$ at $37^{\circ} \mathrm{C}$ ) or DMSO as negative control. Oligonucleotides complementary to different regions of PR were $5^{\prime}$-radiolabeled, hybridized with the template RNA, and extended using Superscript III retrotranscriptase (Sigma-Aldrich) using the manufacturer indications. The oligonucleotides were as follows: 5'-CAGATAACACTTAAAAC
AGAGTGAT and 5'-GCTTGCAATAATCCTAATGTAC. Samples were loaded in a 7\% acrylamide/urea denaturing gel, dried and visualized in a PhosphorImager. A ladder consisting of a sequencing reaction using the same oligos on the plasmids from which the template RNAs were synthesized, was loaded in parallel to locate the positions of the NIMIA-reactive nucleotides. These sequencing reactions were performed using the Thermo Sequenase Cycle Seq kit (USB). Bands were quantified and the data fed into RNA fold to obtain a secondary structure model.

\section{SUPPLEMENTAL MATERIAL}

Supplemental material is available for this article.

\section{ACKNOWLEDGMENTS}

We dedicate this manuscript to the memory of Catherine Papin. We thank Krystyna Keleman for the Orb2-GFP flies, and Bill Marzluff, Mariana Wolfner, Quinhua Liu, Terry Orr-Weaver, and Elmar Wahle for reagents. We are grateful to Giovanni Bussoti and Cedric Notredame for help with RNA-fold, to Encarna MartínezSánchez for guidance with SHAPE, and to Uwe Kühn for advice on global poly(A) tail assessment. We thank the CRG Protein Service and the CRG/UPF Proteomics Unit for antibody purification, protein production and identification. A.V. was supported by a FPI fellowship from the Spanish Ministry of Economy and Competitiveness (MINECO). This work was supported by MINECO and the European Regional Development Fund (ERDF) under BFU2012-37135, BFU2015-68741, and Consolider CSD2009-00080 grants to F.G., and by the CNRS UMR9002, ANR (ANR-2010-BLAN-1201-01 and ANR-15-CE12-0019-01), and FRM (Equipe FRM 2013 DEQ20130326534) to M.S. We acknowledge support of MINECO "Centro de Excelencia Severo Ochoa 2013-2017,” SEV-2012-0208.

Received December 20, 2017; accepted January 4, 2018.

\section{REFERENCES}

Abaza I, Coll O, Patalano S, Gebauer F. 2006. Drosophila UNR is required for translational repression of male-specific lethal $2 \mathrm{mRNA}$ during regulation of X-chromosome dosage compensation. Genes Dev 20: 380-389.

Barckmann B, Simonelig M. 2013. Control of maternal mRNA stability in germ cells and early embryos. Biochim Biophys Acta 1829: 714-724.

Barnard DC, Ryan K, Manley JL, Richter JD. 2004. Symplekin and xGLD-2 are required for CPEB-mediated cytoplasmic polyadenylation. Cell 119: 641-651.

Benoit P, Papin C, Kwak JE, Wickens M, Simonelig M. 2008. PAP- and GLD-2-type poly(A) polymerases are required sequentially in cytoplasmic polyadenylation and oogenesis in Drosophila. Development 135: 1969-1979.

Chang JS, Tan L, Schedl P. 1999. The Drosophila CPEB homolog, orb, is required for oskar protein expression in oocytes. Dev Biol 215: 91-106.

Coll O, Villalba A, Bussotti G, Notredame C, Gebauer F. 2010. A novel, noncanonical mechanism of cytoplasmic polyadenylation operates in Drosophila embryogenesis. Genes Dev 24: 129-134.

Cui J, Sackton KL, Horner VL, Kumar KE, Wolfner MF. 2008. Wispy, the Drosophila homolog of GLD-2, is required during oogenesis and egg activation. Genetics 178: 2017-2029. 
Cui J, Sartain CV, Pleiss JA, Wolfner MF. 2013. Cytoplasmic polyadenylation is a major mRNA regulator during oogenesis and egg activation in Drosophila. Dev Biol 383: 121-131.

de Moor CH, Richter JD. 1999. Cytoplasmic polyadenylation elements mediate masking and unmasking of cyclin B1 mRNA. EMBO J 18: 2294-2303.

Dufourt J, Bontonou G, Chartier A, Jahan C, Meunier AC, Pierson S, Harrison PF, Papin C, Beilharz TH, Simonelig M. 2017. piRNAs and Aubergine cooperate with Wispy poly(A) polymerase to stabilize mRNAs in the germ plasm. Nat Commun 8: 1305.

Eckmann CR, Rammelt C, Wahle E. 2011. Control of poly(A) tail length. Wiley Interdiscip Rev RNA 2: 348-361.

Eichhorn SW, Subtelny AO, Kronja I, Kwasnieski JC, Orr-Weaver TL, Bartel DP. 2016. mRNA poly(A)-tail changes specified by deadenylation broadly reshape translation in Drosophila oocytes and early embryos. Elife 5: e16955.

Elewa A, Shirayama M, Kaymak E, Harrison PF, Powell DR, Du Z, Chute CD, Woolf H, Yi D, Ishidate T, et al. 2015. POS-1 promotes endo-mesoderm development by inhibiting the cytoplasmic polyadenylation of neg-1 mRNA. Dev Cell 34: 108-118.

Gebauer F, Corona DF, Preiss T, Becker PB, Hentze MW. 1999. Translational control of dosage compensation in Drosophila by Sex-lethal: cooperative silencing via the $5^{\prime}$ and $3^{\prime}$ UTRs of $m s l-2$ mRNA is independent of the poly(A) tail. EMBO J 18: 6146-6154.

Grabek KR, Diniz Behn C, Barsh GS, Hesselberth JR, Martin SL. 2015. Enhanced stability and polyadenylation of select mRNAs support rapid thermogenesis in the brown fat of a hibernator. Elife 4: $\mathrm{e} 04517$.

Hafer N, Xu S, Bhat KM, Schedl P. 2011. The Drosophila CPEB protein Orb2 has a novel expression pattern and is important for asymmetric cell division and nervous system function. Genetics 189: 907-921.

Hennig J, Militti C, Popowicz GM, Wang I, Sonntag M, Geerlof A, Gabel F, Gebauer F, Sattler M. 2014. Structural basis for the assembly of the Sxl-Unr translation regulatory complex. Nature 515: 287-290.

Ivshina M, Lasko P, Richter JD. 2014. Cytoplasmic polyadenylation element binding proteins in development, health, and disease. Annu Rev Cell Dev Biol 30: 393-415.

Jänicke A, Vancuylenberg J, Boag PR, Traven A, Beilharz TH. 2012. ePAT: a simple method to tag adenylated RNA to measure poly (A)-tail length and other 3' RACE applications. RNA 18: 1289-1295.

Joly W, Chartier A, Rojas-Rios P, Busseau I, Simonelig M. 2013. The CCR4 deadenylase acts with Nanos and Pumilio in the fine-tuning of Mei-P26 expression to promote germline stem cell self-renewal. Stem Cell Rep 1: 411-424.

Kim KW, Nykamp K, Suh N, Bachorik JL, Wang L, Kimble J. 2009. Antagonism between GLD-2 binding partners controls gamete sex. Dev Cell 16: 723-733.

Kojima S, Sher-Chen EL, Green CB. 2012. Circadian control of mRNA polyadenylation dynamics regulates rhythmic protein expression. Genes Dev 26: 2724-2736.

Krüttner S, Stepien B, Noordermeer JN, Mommaas MA, Mechtler K, Dickson BJ, Keleman K. 2012. Drosophila CPEB Orb2A mediates memory independent of its RNA-binding domain. Neuron 76: 383-395.

Lee YS, Nakahara K, Pham JW, Kim K, He Z, Sontheimer EJ, Carthew RW. 2004. Distinct roles for Drosophila Dicer-1 and Dicer-2 in the siRNA/miRNA silencing pathways. Cell 117: 69-81.

Lim DH, Kim J, Kim S, Carthew RW, Lee YS. 2008. Functional analysis of dicer-2 missense mutations in the siRNA pathway of Drosophila. Biochem Biophys Res Commun 371: 525-530.

Lim DH, Oh CT, Lee L, Hong JS, Noh SH, Hwang S, Kim S, Han SJ, Lee YS. 2011. The endogenous siRNA pathway in Drosophila impacts stress resistance and lifespan by regulating metabolic homeostasis. FEBS Lett 585: 3079-3085.

Lim J, Lee M, Son A, Chang H, Kim VN. 2016. mTAIL-seq reveals dynamic poly(A) tail regulation in oocyte-to-embryo development. Genes Dev 30: 1671-1682.

Liu Q, Rand TA, Kalidas S, Du F, Kim HE, Smith DP, Wang X. 2003. R2D2, a bridge between the initiation and effector steps of the Drosophila RNAi pathway. Science 301: 1921-1925.
Liu X, Jiang F, Kalidas S, Smith D, Liu Q. 2006. Dicer-2 and R2D2 coordinately bind siRNA to promote assembly of the siRISC complexes. RNA 12: 1514-1520.

Marques JT, Kim K, Wu PH, Alleyne TM, Jafari N, Carthew RW. 2010. Loqs and R2D2 act sequentially in the siRNA pathway in Drosophila. Nat Struct Mol Biol 17: 24-30.

Minasaki R, Eckmann CR. 2012. Subcellular specialization of multifaceted $3^{\prime}$ end modifying nucleotidyltransferases. Curr Opin Cell Biol 24: 314-322.

Nishida KM, Miyoshi K, Ogino A, Miyoshi T, Siomi H, Siomi MC. 2013. Roles of R2D2, a cytoplasmic D2 body component, in the endogenous siRNA pathway in Drosophila. Mol Cell 49: 680691.

Norvell A, Wong J, Randolph K, Thompson L. 2015. Wispy and Orb cooperate in the cytoplasmic polyadenylation of localized gurken mRNA. Dev Dyn 244: 1276-1285.

Okamura K, Ishizuka A, Siomi H, Siomi MC. 2004. Distinct roles for Argonaute proteins in small RNA-directed RNA cleavage pathways. Genes Dev 18: 1655-1666.

Pesin JA, Orr-Weaver TL. 2007. Developmental role and regulation of cortex, a meiosis-specific anaphase-promoting complex/cyclosome activator. PLoS Genet 3: e202.

Rangan P, DeGennaro M, Jaime-Bustamante K, Coux RX, Martinho RG, Lehmann R. 2009. Temporal and spatial control of germ-plasm RNAs. Curr Biol 19: 72-77.

Rørth P. 1998. Gal4 in the Drosophila female germline. Mech Dev 78: 113-118.

Rybak-Wolf A, Jens M, Murakawa Y, Herzog M, Landthaler M, Rajewsky N. 2014. A variety of dicer substrates in human and C. elegans. Cell 159: 1153-1167.

Siomi MC, Tsukumo H, Ishizuka A, Nagami T, Siomi H. 2005. A potential link between transgene silencing and poly(A) tails. RNA 11: 1004-1011.

Subtelny AO, Eichhorn SW, Chen GR, Sive H, Bartel DP. 2014. Poly(A)tail profiling reveals an embryonic switch in translational control. Nature 508: 66-71.

Sullivan KD, Steiniger M, Marzluff WF. 2009. A core complex of CPSF73, CPSF100, and Symplekin may form two different cleavage factors for processing of poly(A) and histone mRNAs. Mol Cell 34: 322-332.

Vardy L, Orr-Weaver TL. 2007. The Drosophila PNG kinase complex regulates the translation of cyclin B. Dev Cell 12: 157-166.

Villalba A, Coll O, Gebauer F. 2011. Cytoplasmic polyadenylation and translational control. Curr Opin Genet Dev 21: 452-457.

Vishnu MR, Sumaroka M, Klein PS, Liebhaber SA. 2011. The poly(rC)binding protein $\mathrm{\alpha CP} 2$ is a noncanonical factor in X. laevis cytoplasmic polyadenylation. $R N A$ 17: $944-956$.

Wahle E, Winkler GS. 2013. RNA decay machines: deadenylation by the Ccr4-not and Pan2-Pan3 complexes. Biochim Biophys Acta 1829: 561-770.

Wang Z, Wu D, Liu Y, Xia X, Gong W, Qiu Y, Yang J, Zheng Y, Li J, Wang YF, et al. 2015. Drosophila Dicer-2 has an RNA interference-independent function that modulates Toll immune signaling. Sci Adv 1: e1500228.

Weill L, Belloc E, Bava FA, Méndez R. 2012. Translational control by changes in poly(A) tail length: recycling mRNAs. Nat Struct Mol Biol 19: 577-585.

Wilkinson KA, Merino EJ, Weeks KM. 2006. Selective 2'-hydroxyl acylation analyzed by primer extension (SHAPE): quantitative RNA structure analysis at single nucleotide resolution. Nat Protoc 1: $1610-1616$.

Yamagishi R, Tsusaka T, Mitsunaga H, Maehata T, Hoshino S. 2016. The STAR protein QKI-7 recruits PAPD4 to regulate post-transcriptional polyadenylation of target mRNAs. Nucleic Acids Res 44: 2475-2490.

Ye X, Liu Q. 2008. Expression, purification, and analysis of recombinant Drosophila Dicer-1 and Dicer-2 enzymes. Methods Mol Biol 442: 11-27.

Zhang X, Virtanen A, Kleiman FE. 2010. To polyadenylate or to deadenylate: that is the question. Cell Cycle 9: 4437-4449. 

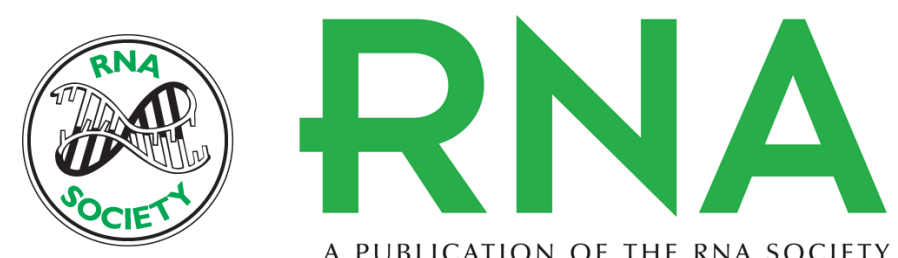

A PUBLICATION OF THE RNA SOCIETY

\section{Dicer-2 promotes mRNA activation through cytoplasmic polyadenylation}

Olga Coll, Tanit Guitart, Ana Villalba, et al.

RNA 2018 24: 529-539 originally published online January 9, 2018

Access the most recent version at doi:10.1261/rna.065417.117

\section{Supplemental http://rnajournal.cshlp.org/content/suppl/2018/01/09/rna.065417.117.DC1 Material}

References This article cites 51 articles, 16 of which can be accessed free at: http://rnajournal.cshlp.org/content/24/4/529.full.html\#ref-list-1

Open Access Freely available online through the RNA Open Access option.

Creative This article, published in $R N A$, is available under a Creative Commons License Commons (Attribution 4.0 International), as described at

License http://creativecommons.org/licenses/by/4.0/.

Email Alerting Receive free email alerts when new articles cite this article - sign up in the box at the Service top right corner of the article or click here.

To subscribe to $R N A$ go to:

http://rnajournal.cshlp.org/subscriptions

(C) 2018 Coll et al.; Published by Cold Spring Harbor Laboratory Press for the RNA Society 